\title{
Electron ionization mass spectral fragmentation study of sulfation derivatives of polychlorinated biphenyls Xueshu Li1 ${ }^{1,2}$, Larry W Robertson ${ }^{1}$ and Hans-Joachim Lehmler*1
}

\author{
Address: ${ }^{1}$ Department of Occupational and Environmental Health, College of Public Health, The University of Iowa, Iowa City, IA 52242, USA \\ and ${ }^{2}$ Department of Chemistry, Iowa State University, Ames, IA 50011, USA \\ Email: Xueshu Li -xueshu@iastate.edu; Larry W Robertson - larry-robertson@uiowa.edu; Hans-Joachim Lehmler* - hans-joachim- \\ lehmler@uiowa.edu \\ * Corresponding author
}

Published: 9 March 2009

Chemistry Central Journal 2009, 3:5 doi: I0.1 186/1752-153X-3-5

This article is available from: http://journal.chemistrycentral.com/content/3/1/5

(C) $2009 \mathrm{Li}$ et al
Received: 23 January 2009

Accepted: 9 March 2009

\begin{abstract}
Background: Polychlorinated biphenyls are persistent organic pollutants that can be metabolized via hydroxylated PCBs to PCB sulfate metabolites. The sensitive and selective analysis of PCB sulfate monoesters by gas chromatography-mass spectrometry (GC-MS) requires their derivatization, for example, as PCB 2,2,2-trichloroethyl (TCE) sulfate monoesters. To aid in the identification of unknown PCB sulfate metabolites isolated from biological samples, the electron impact MS fragmentation pathways of selected PCB TCE sulfate diesters were analyzed and compared to the fragmentation pathways of the corresponding methoxylated PCBs.
\end{abstract}

Results: The most abundant and characteristic fragment ions of PCB TCE sulfate diesters were formed by releasing $\mathrm{CHCCl}_{3}, \mathrm{SO}_{3}, \mathrm{HCl}_{2}$ and/or $\mathrm{CCl}_{3}$ from the TCE sulfate moiety and $\mathrm{Cl}_{2}, \mathrm{HCl}$, ethyne and chloroethyne from an intermediate phenylcyclopentadienyl cation. The fragmentation pattern depended on the degree of chlorination and the position of the TCE sulfate moiety (i.e., ortho vs. meta/para to the second phenyl ring), but were independent of the chlorine substitution pattern. These fragmentation pathways are similar to the fragmentation pathways of structurally related methoxylated PCBs.

Conclusion: Knowledge of the fragmentation patterns of PCB TCE sulfate diesters will greatly aid in determining the position of sulfate moiety (ortho vs. meta/para) of unknown PCB sulfate metabolites isolated from environmental or laboratory samples.

\section{Background}

Polychlorinated biphenyls (PCBs) are a family of manmade chemicals that were sold commercially from the 1920 s to the 1970 s as stabilizing additives in flexible PVC coatings of electrical wiring and in electronic components, cutting oils, flame retardants, hydraulic fluids, sealants, and adhesives $[1,2]$. They are still used as dielectric fluids in transformers and capacitors in the United States. Their large scale use and their physicochemical properties, such as semi-volatility and stability toward biological, chemical and thermal degradation, have resulted in worldwide environmental contamination [1,2]. Since the first identification of PCBs in human and wildlife samples in 1966 [3] the study of PCBs' adverse effects on human health and the environment has received significant attention $[1,2,4,5]$. Laboratory and epidemiological studies have implicated PCBs in a broad range of adverse biological effects, including (neuro-) developmental toxicity [4] and carcinogenesis [5].

PCBs are metabolized by cytochrome P450 (CYP) isoforms, such as CYP2B and CYP1A, to hydroxylated deriv- 
atives (HO-PCBs) [6]. HO-PCBs may be further metabolized by phase II enzymes to PCB sulfates $[7,8]$. Aside from serving as substrates, certain HO-PCBs are inhibitors of sulfotransferases [8-10]. Unfortunately, the role of PCB sulfate metabolites in the disposition and toxicity of PCBs is poorly understood. Therefore, it is necessary to identify and quantify the PCB sulfate conjugates with the help of modern scientific methods, such as mass spectrometry. There are several kinds of ionization methods that can be used in mass spectrometry studies of PCB sulfates, such as electrospray ionization (ESI), matrix assisted laser desorption ionization (MALDI), chemical ionization (CI), atmospheric pressure chemical ionization (APCI), or electron impact (EI). However, it is difficult to identify $\mathrm{PCB}$ sulfate conjugates by mass spectrometry directly due to their amphiphilic and nonvolatile character, and the fragility of the sulfate moiety under typical mass spectrometric conditions. Fortunately, electron impact mass spectrometry, by which abundant fragment ions can be obtained, is a useful and straightforward method to identify the (poly)aryl compounds [1116]. Paulson and co-workers have reported a gas chromatography-mass spectrometry (GC-MS)-based characterization method that converts the sulfate monoester into the corresponding aryl alkyl sulfate diesters, which are stable under temperature programmed GC conditions [17]. Building on this approach, we have explored the utility of 2,2,2-trichloroethyl (TCE)-protected PCB sulfates as potential derivatives for the qualitative and quantitative analysis of PCB sulfate metabolites. Here we report the EIMS fragmentation mechanism of selected PCB TCE sulfate diesters.

\section{Results and discussion}

The PCB 2,2,2-trichloroethyl sulfate diesters 1-10 and selected, structurally-related methoxylated PCBs 11 and 12(Figure 1) were analyzed by electron ionization mass spectrometry (EI-MS). Representative EI-MS spectra are shown in Figures 2, 3, 4 and 5. The MS fragment ions and the corresponding relative abundance are given in Table 1. To simplify the discussion, only ${ }^{35} \mathrm{Cl}$ peaks are discussed for fragment ions with isotopic chlorine atom(s) [18]. The MS fragmentation pathways of compounds $\mathbf{5}$ and $\mathbf{8}$ were investigated as typical examples of the fragmentation of TCE PCB sulfate diesters. In addition, the effects of the degree of chlorination and also the chlorine and "OR" substitution patterns $\left(-\mathrm{OR}=-\mathrm{OMe}\right.$ or $\left.-\mathrm{OSO}_{3} \mathrm{TCE}\right)$ on the MS fragmentation pathways are discussed. Here we will first discuss the loss of the TCE-sulfate moiety from the parent ion to form (chlorinated) phenylcyclopentadienyl cations and then the fragmentation pathways of (chlorinated) phenylcyclopentadienyl cations.

\section{Fragmentation of the parent ion/TCE-sulfate moiety}

The mass spectrum of compound 5 displays its molecular ion 5a with the typical isotope pattern [18] of a pentachlorinated compound at $m / z 448$ (relative abundance, $15 \%$ ) (Figure 2). Scheme 1 illustrates the various fragmentation pathways of this precursor ion. The molecular ion 5a loses a PCB sulfate $\left(\mathrm{ArOSO}_{3}{ }^{-}\right)$group, thus yielding TCE group-derived fragment ions. These ions, $\left[\mathrm{CH}_{2} \mathrm{CCl}_{3}\right]^{+}$and $\left[\mathrm{CH}=\mathrm{CCl}_{2}\right]^{+}$, are observed at $\mathrm{m} / z 131(6 \%)$ and $95(7 \%)$, respectively.

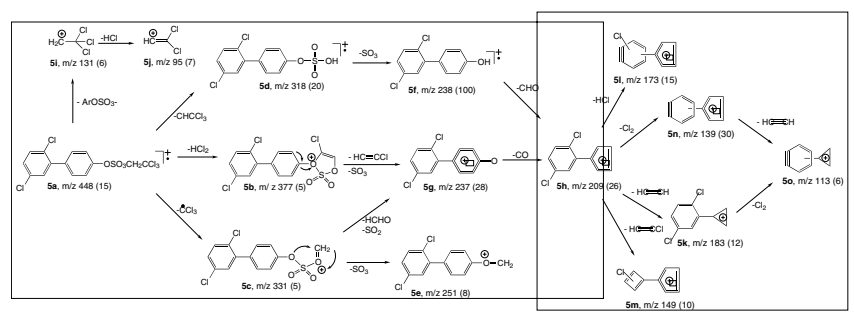

Scheme I: Principal El-MS fragmentation pathways of sulfuric acid 2',5'dichlorobiphenyl-4yl ester 2,2,2-trichloroethyl ester $\mathbf{5}$.

More complex fragmentation patterns are observed for the fragmentation of the $-\mathrm{OSO}_{3}$-TCE group. The abundant fragment ion $5 \mathrm{~g}(\mathrm{~m} / \mathrm{z} 237,28 \%)$ can be formed by two fragmentation pathways from precursor ion 5 a. One pathway involves the release of $\mathrm{HCl}$ and $\mathrm{Cl}$ from precursor ion $\mathbf{5 a}$, leading to an unstable cyclic fragment ion $\mathbf{5 b}(\mathrm{m} / \mathrm{z}$ $377,5 \%)$. In turn, fragment ion $\mathbf{5 b}$ produces the fragment ion $5 \mathrm{~g}$ after releasing chloroethyne and $\mathrm{SO}_{3}$. The other pathway resulting in the formation of fragment ion $\mathbf{5 g}$ involves the removal of two neutral molecules, HCHO and $\mathrm{SO}_{2}$, from the daughter fragment ion $5 \mathrm{c}(\mathrm{m} / z 331$, $5 \%$ ), which is formed by releasing the free radical group $\mathrm{CCl}_{3}$ from fragment ion $\mathbf{5 a}$.

Alternatively, the fragment ion $5 \mathrm{c}$ can also produce the daughter fragment ion $5 \mathbf{e}(\mathrm{m} / z 183,12 \%)$ by losing one molecule of $\mathrm{SO}_{3}$. In addition, precursor ion 5 a yields the daughter ion $\mathbf{5 d}$ by losing a $\mathrm{CHCCl}_{3}$ fragment. The basic fragment ion $\mathbf{5 f}$ at $m / z 238$ is produced from the daughter ion $5 \mathbf{d}(\mathrm{m} / z 318,20 \%)$ by releasing one molecule of $\mathrm{SO}_{3}$. Fragment ions $5 \mathrm{f}$ and $5 \mathrm{~g}$ can produce the important fragment ion $5 \mathbf{h}$ at $\mathrm{m} / z 209$ with a relative abundance of $26 \%$ by losing a $\mathrm{CHO}$ or $\mathrm{CO}$ fragment, respectively.

The same fragmentation pathways are observed for the TCE PCB sulfates diesters 1 and 3-10. The only exception is compound 2, which has the TCE sulfate group in ortho position to the other phenyl ring. The mass spectrum of compounds $\mathbf{2}$ is distinctively different from the mass spectrum of its isomer, compound 3 (Figures 3 and 4). As shown in Scheme 2, the basic fragment ion of compound $\mathbf{2}$ is the stable dibenzofuran ion $\mathbf{2 f}$. Fragment ion $\mathbf{2} \mathbf{f}$ is formed from the parent ion $2 \mathrm{a}(\mathrm{m} / \mathrm{z} 414$; relative abundance, $21 \%)$ by sequential loss of $\mathrm{CHCCl}_{3}(2 \mathrm{~d}, \mathrm{~m} / z$ 284; 


\begin{tabular}{|c|c|c|}
\hline No. & Name & Structure \\
\hline 1 & $\begin{array}{l}\text { Sulfuric acid biphenyl-4-yl ester 2,2,2- } \\
\text { trichloro-ethyl }\end{array}$ & \\
\hline 2 & $\begin{array}{l}\text { Sulfuric acid 4'-chloro-biphenyl-2-yl ester } \\
\text { 2,2,2-trichloro-ethyl ester }\end{array}$ & \\
\hline 3 & $\begin{array}{l}\text { Sulfuric acid 4'-chloro-biphenyl-3-yl ester } \\
\text { 2,2,2-trichloro-ethyl ester }\end{array}$ & \\
\hline 4 & $\begin{array}{l}\text { Sulfuric acid 4'-chloro-biphenyl-4-yl ester } \\
\text { 2,2,2-trichloro-ethyl ester }\end{array}$ & \\
\hline 5 & $\begin{array}{l}\text { Sulfuric acid } 2^{\prime}, 5^{\prime} \text {-dichloro-biphenyl-4-yl ester } \\
\text { 2,2,2-trichloro-ethyl ester }\end{array}$ & \\
\hline 6 & $\begin{array}{l}\text { Sulfuric acid 2,4'-dichloro-biphenyl-4-yl ester } \\
\text { 2,2,2-trichloro-ethyl ester }\end{array}$ & \\
\hline 7 & $\begin{array}{l}\text { Sulfuric acid } 3^{\prime}, 4^{\prime} \text {-dichloro-biphenyl-4-yl ester } \\
\text { 2,2,2-trichloro-ethyl ester }\end{array}$ & \\
\hline 8 & $\begin{array}{l}\text { Sulfuric acid 2',3,5'-trichloro-biphenyl-4-yl } \\
\text { ester 2,2,2-trichloro-ethyl ester }\end{array}$ & \\
\hline 9 & $\begin{array}{l}\text { Sulfuric acid 2',3,5,5'-tretrachloro-biphenyl-4- } \\
\text { yl ester 2,2,2-trichloro-ethyl ester }\end{array}$ & \\
\hline 10 & $\begin{array}{l}\text { Sulfuric acid } 2^{\prime}, 3,4^{\prime}, 5 \text {-tretrachloro-biphenyl-4- } \\
\text { yl ester 2,2,2-trichloro-ethyl ester }\end{array}$ & \\
\hline 11 & 4'-Chloro-2-methoxy-biphenyl & \\
\hline 12 & 2', 5'-Dichloro-4-methoxy-biphenyl & \\
\hline 13 & $2^{\prime}, 3,5^{\prime}$-Trichloro-4-methoxy-biphenyl & \\
\hline
\end{tabular}

\section{Figure I}

Structure of the PCB sulfates and the corresponding methoxylated PCBs. 


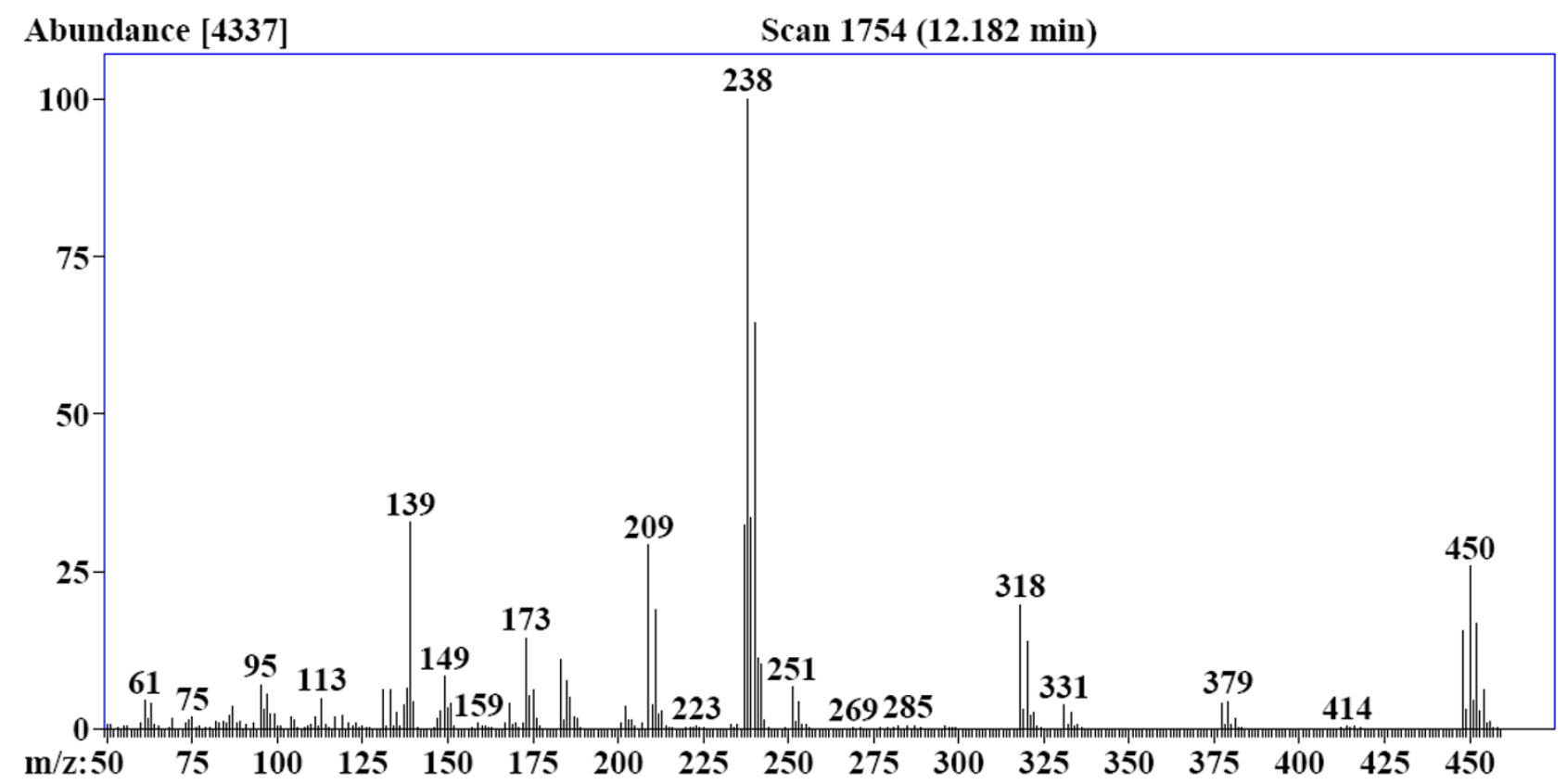

Figure 2

EI mass spectrum of compound 5.

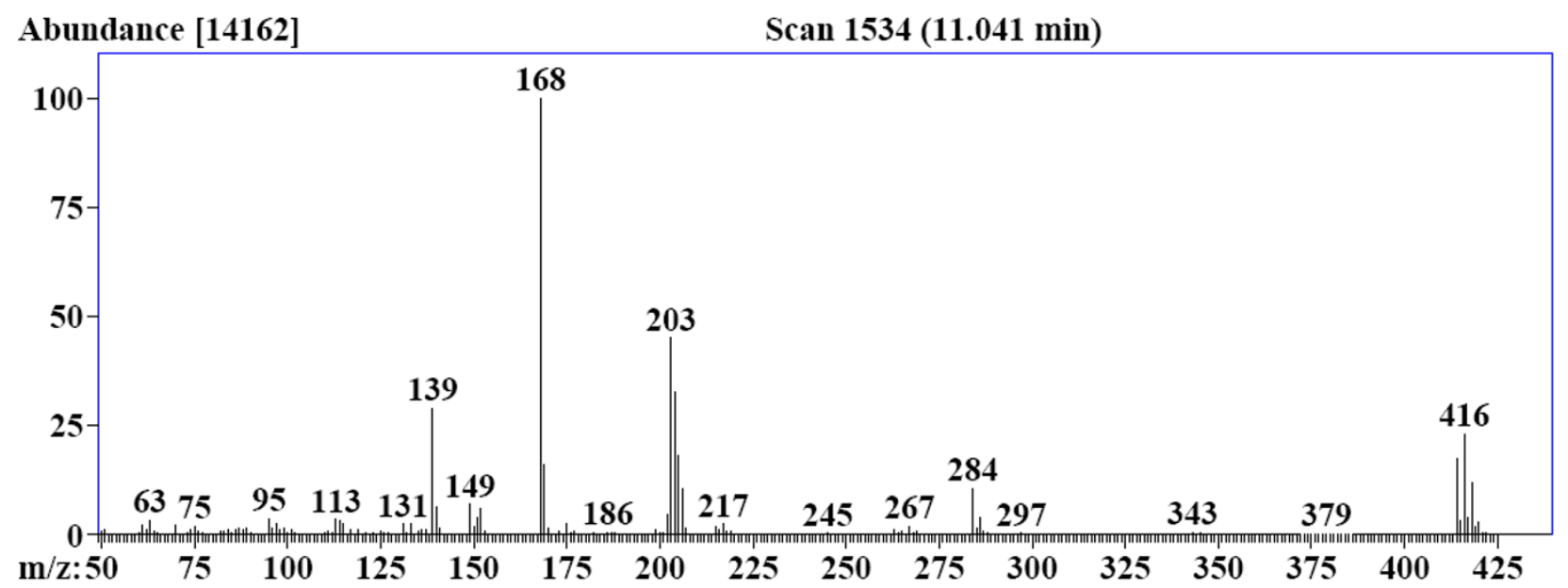

Figure 3

EI Mass spectrum of compound 2. 


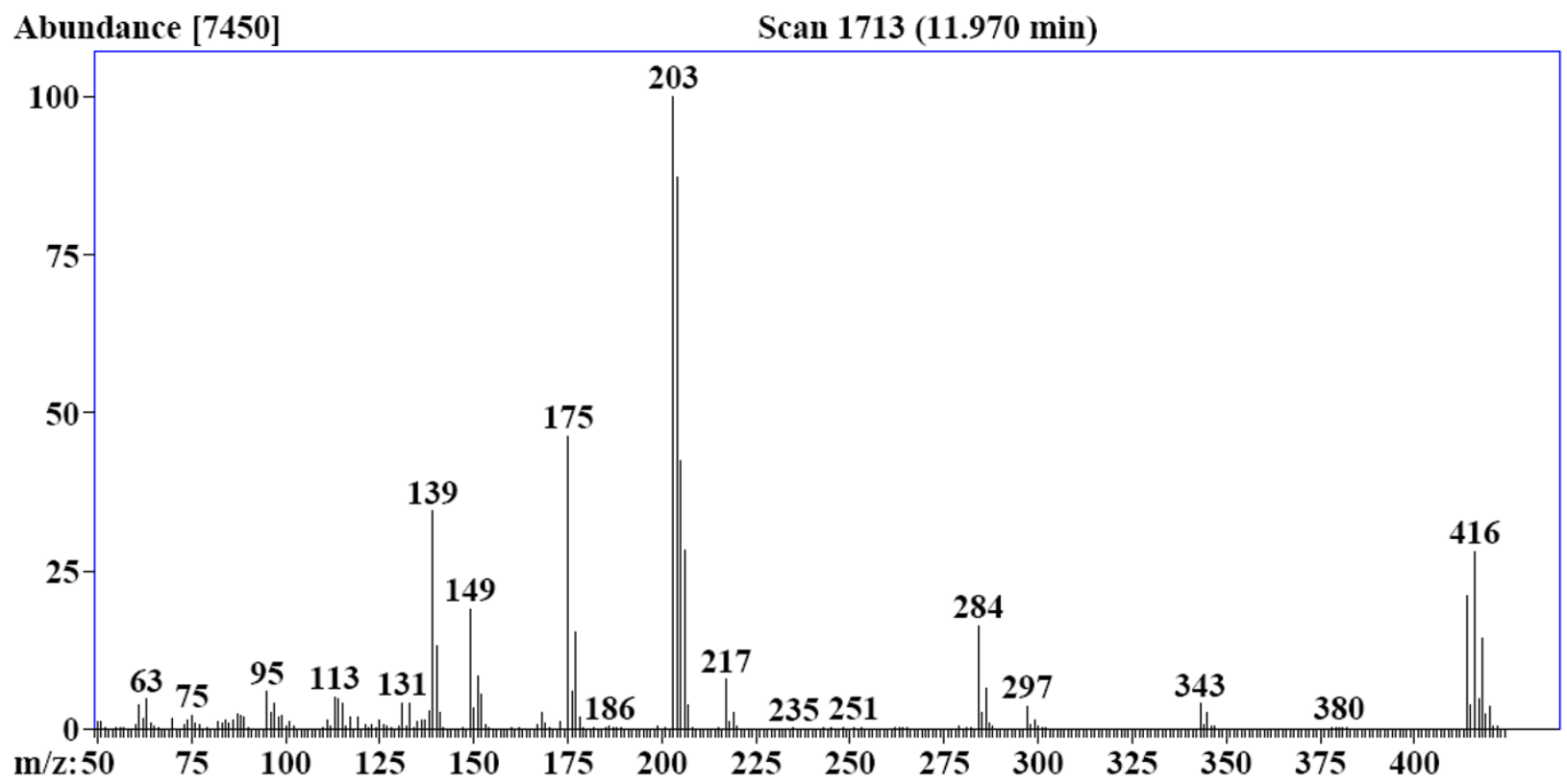

Figure 4

EI mass spectrum of compound 3.

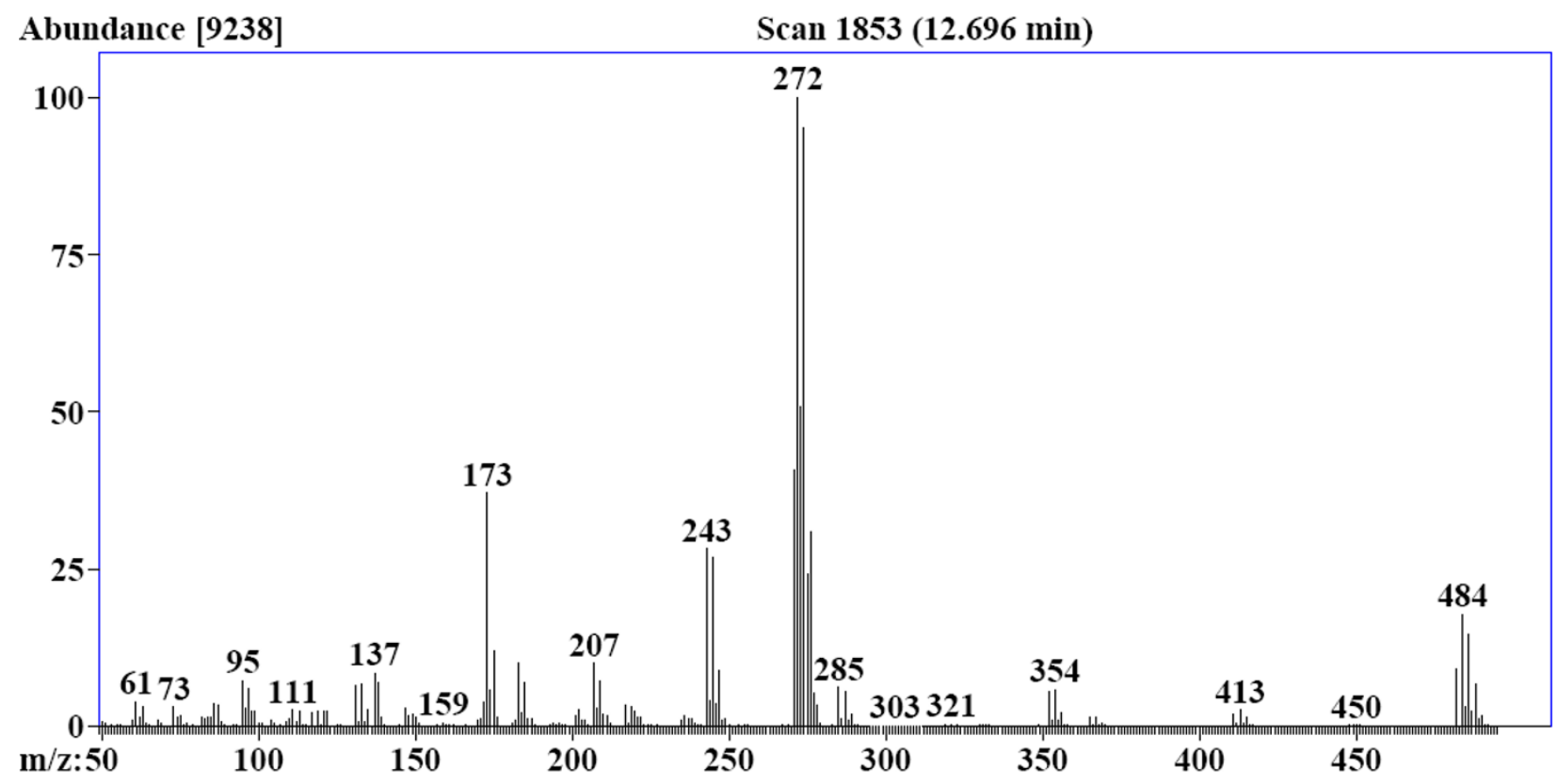

Figure 5

El mass spectrum of compound 8 . 
Table I: EI-MS data of PCB sulfates and methoxylated PCBs obtained from GC-MS.

\begin{tabular}{|c|c|c|c|}
\hline No. & Fragment ions and relative abundance $(\mathrm{m} / \mathrm{z}, \%)$ & No. & Fragment ions and relative abundance $(\mathrm{m} / \mathrm{z}, \%)$ \\
\hline $\mathbf{I}$ & $\begin{array}{l}380(25), 309(7)^{\#}, 263(5)^{*}, 250(15)^{\$}, 183(8), 170(90), 169(100) \\
152(6), 14|(51), 13|(3), I 15(45), 95(7)\end{array}$ & 8 & $\begin{array}{l}482(10), 41\left|(4)^{\#}, 365(3)^{*}, 352(7)^{\$}, 285(8), 272(100), 27\right| \\
(40), 243(26), 217(4), 207(10), 183(10), 173(38), 147(4), \\
|37(10), 13|(7), 95(8)\end{array}$ \\
\hline 2 & $\begin{array}{l}414(21), 343(<1)^{\#}, 297(<1)^{*}, 284(10)^{\$}, 217(2), 204(28), 203(45) \\
175(2), 168(100), 149(5), 139(27), 131 \text { (2), II3 (2), } 95(3)\end{array}$ & 9 & $\begin{array}{l}516(8), 445(<1) \#, 399(2)^{*}, 386(<<1)^{\$}, 319(2), 306(55) \\
305(75), 277(20), 241(5), 217(7), 207(28), 131(5), 95(5)\end{array}$ \\
\hline 3 & $\begin{array}{l}414(24), 343(5)^{\#}, 297(5)^{*}, 284(16)^{\$}, 217(8), 204(85), 203(100) \\
175(35), 149(15), 139(26), 13 \text { I (8), II3 (5), } 95(7)\end{array}$ & 10 & $\begin{array}{l}516(6), 445(<1) \#, 399(2)^{*}, 386(<<1) \$, 319(2), 306(35) \\
305(80), 277(18), 241(7), 217(7), 207(33), 131(8), 95(11)\end{array}$ \\
\hline 4 & $\begin{array}{l}414(23), 343(5)^{\#,}, 297(5)^{*}, 284(16)^{\$}, 217(8), 204(87), 203(100) \text {, } \\
175(45), \text { I } 49(20), 139(35), I 3 \mid(5), \text { I I } 3(5), 95(7)\end{array}$ & II & $\begin{array}{l}218 \text { (95), } 204(5), 203(13), 183(9), 175(4), 168(100), 149 \\
(6), 139(38), 113(4)\end{array}$ \\
\hline 5 & $\begin{array}{l}448(15), 377(5)^{\#}, 33\left|(5)^{*}, 318(20)^{\$}, 25\right|(8), 238(100), 237(28), \\
209(26), 183(12), 173(15), 149(10), 139(30), 13 \mid(6), 113(6), 95 \\
(7)\end{array}$ & 12 & $\begin{array}{l}252(100), 238(8), 237(40), 209(35), 183(10), 173(12), 149 \\
(6), 139(25), 113(5)\end{array}$ \\
\hline 6 & 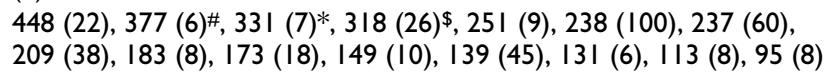 & 13 & $\begin{array}{l}286(100), 27 \mid(40), 243(35), 217(5), 207(12), 183(10), 173 \\
(33), 147(4), 137(10)\end{array}$ \\
\hline 7 & 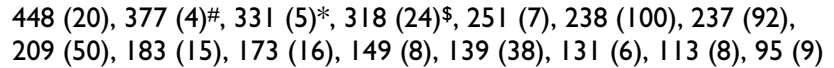 & & \\
\hline
\end{tabular}

Note: The relative abundance of fragment ions:\# $\left[\mathrm{M}-\mathrm{HCl}_{2}\right]^{+} ; *\left[\mathrm{M}-\mathrm{CCl}_{3}\right]^{+} ;{ }^{\$}\left[\mathrm{ArOSO}_{3} \mathrm{H}\right]^{+}$.

relative abundance, $10 \%), \mathrm{SO}_{3}(2 \mathbf{e}, \mathrm{m} / z$ 204; relative abundance, $28 \%)$ and $\mathrm{HCl}(2 \mathrm{f}, \mathrm{m} / \mathrm{z} 168$; relative abundance, $100 \%$ ). The stable dibenzofuran cation $2 \mathrm{f}$ is also formed as the base peak ion in the fragmentation pathways of corresponding methoxylated PCB 11 (Table 1). Similarly, other 2-methoxy PCB derivatives also form a stable dibenzofuran cation after losing chlorine atom and methyl group [19].

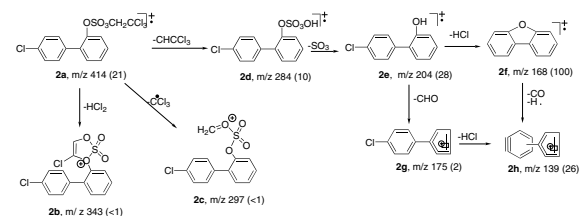

Scheme 2: Principal El-MS fragmentation pathways of sulfuric acid 4'dichlorobiphenyl-2-yl ester 2,2,2-trichloroethyl ester $\mathbf{2}$.

The relative abundance of several fragment ions depends on the position of the - $\mathrm{OSO}_{3}$-TCE group and the chlorine substitution pattern. The relative abundance of the [M$\left.\mathrm{HCl}_{2}\right]^{+}$and $\left[\mathrm{M}-\mathrm{CCl}_{3}\right]^{+}$fragment ions of compound 2, 9 and $\mathbf{1 0}$ are lower compared to all other TCE PCB sulfate diesters (Table 1). This lower relative abundance is due to steric and/or electronic effects resulting from the ortho phenyl substituent in compound 2 or the two ortho chlorine substituents in compounds 9 and 10. In addition, the relative abundance of fragment ion $\left[\mathrm{ArOSO}_{3} \mathrm{H}\right]^{+}$of the TCE PCB sulfate diesters 9 and $\mathbf{1 0}$ is low compared to the corresponding fragment ion of the other TCE PCB sulfate diesters, with only a trace of the respective ions being observed (Table 1). For example, the relative abundance of $\left[\mathrm{ArOSO}_{3} \mathrm{H}\right]+\mathbf{5 d}$ is $20 \%$, whereas the abundance of the corresponding fragment ions of compounds 9 and $\mathbf{1 0}$ is $<<1 \%$. Since compounds 9 and 10 have two chlorine substituents in the phenyl ring with the $-\mathrm{OSO}_{3} \mathrm{TCE}$ group, the low relative abundance of fragment ion $\left[\mathrm{ArOSO}_{3} \mathrm{H}\right]^{+}$suggests that the sulfate group of both compounds is less stable, possibly because of the comparatively high $\mathrm{pK}_{\mathrm{a}}$ value of the Ar-OH group [20]. This observation is in agreement with the decreasing chemical stability of aryl sulfate monoesters with increasing acidity of the phenolic aryl group [21].

\section{Fragmentation of the chlorinated phenylcyclopentadienyl cations}

The fragmentation pathway of the chlorinated biphenyl moiety appears to depend on the degree of chlorination but not the chlorine substitution pattern. For compound 5, the principal fragmentation pathways of the dichlorinated precursor ion $\mathbf{5 h}$ is shown in Scheme 1. Fragment ion 5 h can produce the fragment ions $5 \mathbf{l}(\mathrm{m} / z 173,5 \%)$ and $5 \mathrm{~m}(\mathrm{~m} / \mathrm{z} 149,10 \%)$ by releasing a neutral $\mathrm{HCl}$ or chloroethyne molecule. Precursor ion $5 \mathrm{~h}$ can also sequentially lose neutral $\mathrm{Cl}_{2}$ and ethyne molecules to give the fragment ion 5 o $(m / z 113,6 \%)$ via 5 n $(m / z 139,30 \%)$. Alternatively, fragment ion 50 can be formed in the reverse order via $5 \mathbf{k}(\mathrm{m} / z 183,12 \%)$.

For comparison the principal fragmentation pathway of the trichlorinated precursor ion $8 \mathrm{a}$ is shown in Scheme 3 (see Figure 5 for the mass spectrum of compound 8 ). There are two important fragment ions, 8c $(\mathrm{m} / z 147,4 \%)$ and $8 \mathbf{e}(\mathrm{m} / \mathrm{z} 137,10 \%)$, which are granddaughter ions of precursor ion $8 \mathbf{a}(\mathrm{m} / z 243,26 \%)$. Precursor ion 8 a can lose one molecule of $\mathrm{HCl}$ to yield its daughter ion $8 \mathbf{d}(\mathrm{m} /$ $z$ 207, 10\%), which subsequently produces the fragment ions $8 \mathrm{c}$ and $8 \mathrm{e}$ by releasing chloroethyne or $\mathrm{Cl}_{2}$. Similarly, precursor ion $8 \mathrm{f}(\mathrm{m} / \mathrm{z} 173,38 \%)$, which is obtained by releasing one molecule of $\mathrm{Cl}_{2}$ from its parent ion $8 \mathrm{a}$, can release $\mathrm{HCl}$ and ethyne to give daughter ions $8 \mathbf{e}$ or $\mathbf{8 c}$, 
respectively. Finally, precursor ion 8a can form granddaughter ion 8c via two pathways. One is via daughter ion $8 \mathbf{b}(m / z 183,10 \%)$ by sequentially releasing $\mathrm{HCl}$ and chloroethyne, the other is via daughter ion $8 \mathrm{~g}(\mathrm{~m} / z 217$, $4 \%$ ) by sequential loss of $\mathrm{Cl}_{2}$ and ethyne.

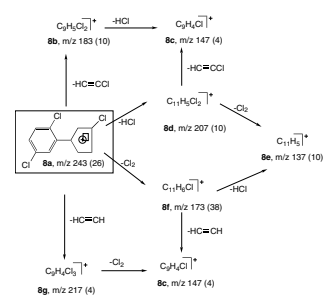

Scheme 3: Principal El-MS fragmentation pathways of phenylcyclopentadienyl cation $8 \mathbf{a}(\mathrm{m} / \mathbf{z} 243)$ formed from 2',3,5'-trichlorobiphenyl-4-yl ester 2,2,2-trichloroethyl ester $\mathbf{8}$. The fragmentation pattern resulting in the formation of $\mathbf{8 a}$ from the corresponding molecular ion is analogous to the pathways shown in Scheme I.

Overall, the chlorine substitution pattern has little-to-no effect on the fragmentation pathways, with the relative weak abundance of some fragment ions of compounds 9 and 10 being one exception. For example, the fragmentation pathways of homologous compounds (such as compounds 5, 6 and 7 with two and compounds 9 and 10 with four chlorine substituents) are very similarly. In contrast, the fragmentation pathways of TCE PCB sulfates diesters investigated become more complex with increasing degree of chlorination in the biphenyl rings (e.g., 5 vs. 8 as discussed above), which is mainly due to the more complex fragmentation of the biphenyl rings part of the TCE PCB sulfates diesters. Similarly, MeO-PCBs, such as 12 and 13, form the chlorinated phenylcyclopentadienyl cations by losing $\mathrm{CO}$ and free radical $\mathrm{CH}_{3}$. The fragmentation patterns of these MeO-PCB-derived phenylcyclopentadienyl cations are similar to the ones observed for the corresponding TCE PCB sulfate diesters and typically depend on the degree of chlorination.

\section{Conclusion}

Electron impact MS fragmentation pathways of a series of PCB TCE sulfate diesters with different degrees of chlorination and substitution patterns were investigated. Representative and abundant fragment ions were formed by releasing $\mathrm{CHCCl}_{3}, \mathrm{SO}_{3}, \mathrm{HCl}_{2}, \mathrm{CCl}_{3}$ from the TCE moiety. While the respective fragmentation pathways were identical for all PCB TCE sulfate diesters investigated, the intensities of one fragment ion, $\left[\mathrm{ArOSO}_{3} \mathrm{H}\right]^{+}$, was significantly lower when two ortho chlorine atoms were present. The instability of this fragment ion is probably a result of the comparatively high acidity resulting from the two chlorine substituents. Loss of the TCE sulfate group, independent of the fragmentation pathway, ultimately resulted in the formation of chlorinated phenylcyclopentadienyl cations. These chlorinated phenylcyclopentadienyl cations in turn formed abundant fragment ions by losing $\mathrm{Cl}_{2}$,
$\mathrm{HCl}$, ethyne and chloroethyne in a degree of chlorinationdependent manner; however, the fragmentation of the phenylcyclopentadienyl cations was independent of the chlorine substitution pattern. Overall, the fragmentation of the phenylcyclopentadienyl cations of the PCB TCE sulfate diesters is comparable to the respective MeO-PCBs.

\section{Experimental}

A series of TCE PCB sulfate diesters 1-10 was synthesized by sulfation of lower chlorinated HO-PCBs with an excess of 2,2,2-trichloroethyl chlorosulfate [22] (1.1 equivalent) in the presence of $4-N, N$-dimethylaminolpyridine (DMAP, 1.5 equivalent) in anhydrous dichloromethane [23]. The corresponding starting materials, including the methoxylated (MeO-)PCBs 11-13, were synthesized as described previously [24]. The structures of all compounds were confirmed by NMR, IR and (HR or LR) MS and are shown in Figure 1. The GC-MS analysis was carried out using an Agilent 6890 N Series network gas chromatograph equipped with a $7683 \mathrm{~B}$ series auto injector (Agilent Technologies, Santa Clara, CA, USA). The GC was interfaced with an Agilent 5975 inert series mass-selective detector (MSD) configured in electron impact (EI) mode. Chromatography was accomplished with a fused silica capillary HP-5 column $(30.0 \mathrm{~m} \times 250 \mu \mathrm{m} \times 0.25 \mu \mathrm{m}$, Agilent, Santa Clara, CA, USA). Helium ( $18.6 \mathrm{ml} / \mathrm{min})$ was used as carrier gas. The oven temperature was ramped over a linear gradient from 50 to $280^{\circ} \mathrm{C}$ at $20^{\circ} \mathrm{C} / \mathrm{min}$, then held for 10 minutes at $280^{\circ} \mathrm{C}$. The injector temperature, ion source temperature and interface temperature were $250^{\circ} \mathrm{C}, 230^{\circ} \mathrm{C}$ and $280^{\circ} \mathrm{C}$, respectively. The comparatively low injector temperature was necessary to avoid decomposition on the PCB TCE sulfate esters.

\section{Competing interests}

The authors declare that they have no competing interests.

\section{Authors' contributions}

XL collected the GC-MS data, performed data analysis, and contributed to drafting the manuscript. HJL and LWR conceived of the study, participated in its design and contributed to drafting the manuscript. All authors read and approved the final manuscript.

\section{Acknowledgements}

This research was supported by grants ES05605, ESOI 2475 and ESOI366 I from the National Institute of Environmental Health Sciences, NIH. Contents of this manuscript are solely the reponsibility of the authors and do not necessarily represent the official views of the NIEHS/NIH.

\section{References}

I. Robertson LW, Hansen LG: Recent advances in the environmental toxicology and health effects of PCBs Lexington: University Press of Kentucky; $200 \mathrm{I}$.

2. Hansen LG: The ortho side of PCBs: Occurrence and disposition Boston: Kluwer Academic Publishers; 1999.

3. Jensen S: Report on a new chemical hazard. New Sci 1966, 32:612. 
4. Kodavanti PRS: Intracellular signaling and developmental neurotoxicity. In Molecular Neurotoxicology: environmental agents and transcription-transduction coupling Edited by: Zawia NH. Boca Roton, FL: CRC press; 2004:15 I-182.

5. Silberhorn EM, Glauert HP, Robertson LW: Carcinogenicity of polyhalogenated biphenyls: PCBs and PBBs. Crit Rev Toxicol 1990, 20:439-496.

6. Kaminsky LS, Kennedy MW, Adams SM, Guengerich FP: Metabolism of Dichlorobiphenyls by Highly Purified Isozymes of RatLiver Cytochrome-P-450. Biochemistry 198I, 20:7379-7384.

7. Sacco JC, Lehmler HJ, Robertson LW, Li WJ, James MO: Glucuronidation of polychlorinated biphenylols and UDP-glucuronic acid concentrations in channel catfish liver and intestine. Drug Metab Dispos 2008, 36:623-630.

8. Liu Y, Apak TI, Lehmler H-J, Robertson LW, Duffel MW: Hydroxylated polychlorinated biphenyls are substrates and inhibitors of human hydroxysteroid sulfotransferase SULT2AI. Chem Res Toxicol 2006, 19:1420-1425.

9. Kester MHA, Bulduk S, Tibboel D, Meinl W, Glatt H, Falany CN, Coughtrie MWH, Bergman A, Safe SH, Kuiper GGJM, Schuur AG, Brouwer A, Visser TJ: Potent inhibition of estrogen sulfotransferase by hydroxylated PCB metabolites: A novel pathway explaining the estrogenic activity of PCBs. Endocrinol 2000, |4I: 1897-1900.

10. Lans MC, Klasson-Wehler E, Willemsen M, Meussen E, Safe S, Brouwer A: Structure-Dependent, Competitive Interaction of Hydroxy-Polychlorobiphenyls, Hydroxy-Dibenzo-P-Dioxins and Hydroxy-Dibenzofurans with Human Transthyretin. Chem Biol Interact 1993, 88:7-21.

II. Prukała D, Sikorski M: Electron ionization mass spectrometric study of substituted alloxazine-5-oxides and iso-alloxazine-5oxide. Rapid Commun Mass Spectrom 2009, 23:619-628.

12. Porto RMD, Perez AR, Vidal MTC, Fraga MG: Qualitative confirmation procedure for ephedrines as acetonide derivatives in doping urine samples by gas chromatography/electron ionization mass spectrometry. Rapid Commun Mass Spectrom 2009, 23:249-257.

13. Porto RMD, Perez AR, Vidal MTC: Electron ionization mass spectra of ephedrines in a doping confirmatory procedure: a curious migration of the trimethylsilyl group in the $\mathbf{N}$-acetylO-trimethylsilyl derivatives. Rapid Commun Mass Spectrom 2007, 21:187|-1876.

14. Opitz J: Electron-impact ionization of benzoic acid, nicotinic acid and their $n$-butyl esters: An approach to regioselective proton affinities derived from ionization and appearance energy data. Int J Mass Spectrom 2007, 265: I- 14.

15. Guo HF, Xing J, Xie CF, Qu JB, Gao YH, Lou HX: Study of bis(bibenzyls) in bryophytes using electron ionization timeof-flight and electrospray ionization triple-quadrupole mass spectrometry. Rapid Commun Mass Spectrom 2007, 2 I:1367-1374.

16. Gomara B, Herrero L, Gonzalez MJ: Feasibility of electron impact and electron capture negative ionisation mass spectrometry for the trace determination of tri- to deca-brominated diphenyl ethers in human samples. Anal Chim Acta 2007, 597:12I-I28.

17. Paulson G, Simpson M, Giddings J, Bakke J, Stolzenberg G: The conversion of aryl sulfate ester to alkyl aryl derivatives suitable for analysis by electron impact mass spectrometry. Biomed Mass Spectrom 1978, 5:413-4I7.

18. Hutzinger O, Sate S, Zitko V: The Chemistry of PCB's Malabar: Robert E. Krieger Publishing Company; 1983.

19. Bergman A, Klasson WE, Kuroki H, Nilsson A: Synthesis and MassSpectrometry of Some Methoxylated Pcb. Chemosphere 1995, 30:1921-1938

20. Tampal N, Lehmler H-J, Espandiari P, Malmberg T, Robertson LW: Glucuronidation of hydroxylated polychlorinated biphenyls (PCBs). Chem Res Toxicol 2002, 15:|259-1266.

21. Brandao TAS, Priebe JP, Damasceno AS, Bortoluzzia AJ, Kirby AJ, Nome F: Bond length-reactivity correlations for sulfate monoesters. The crystal structure of potassium 4-nitrophenyl sulfate, $\mathbf{C}_{6} \mathbf{H}_{4} \mathrm{KNO}_{6} \mathbf{S}$. J Mol Struct 2005, 734:205-209.

22. Furstner A, Domostoj MM, Scheiper B: Total synthesis of dictyodendrin B. I Am Chem Soc 2005, I 27: | |620-I |62I.

23. Liu Y, Lien IFF, Ruttgaizer S, Dove P, Taylor SD: Synthesis and protection of aryl sulfates using the 2,2,2-trichloroethyl moiety. Org Lett 2004, 6:209-2I2.
24. Lehmler HJ, Robertson LW: Synthesis of hydroxylated PCB metabolites with the Suzuki-coupling. Chemosphere 200I, 45: I II9-II27.a

\section{Publish with ChemistryCentral and every scientist can read your work free of charge}

"Open access provides opportunities to our colleagues in other parts of the globe, by allowing anyone to view the content free of charge."

W. Jeffery Hurst, The Hershey Company.

- available free of charge to the entire scientific community

- peer reviewed and published immediately upon acceptance

- cited in PubMed and archived on PubMed Central

- yours - you keep the copyright

Submit your manuscript here:

http://www.chemistrycentral.com/manuscript/

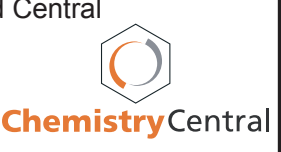

